Original Research Paper

\title{
Nutritional and Fatty Acids Profile Analyses of Commonly Consumed Fresh Water Fish Species in Pakistan
}

\author{
${ }^{1,2}$ Ahsan Hameed, ${ }^{1,2}$ Syed Ammar Hussain, ${ }^{1}$ Muhammed Asim Shabbir ${ }^{1}$ Imran Pasha and ${ }^{2}$ Yuanda Song \\ ${ }^{I}$ National Institute of Food Science and Technology, University of Agriculture Faisalabad, 38000, Pakistan \\ ${ }^{2}$ Colin Ratledge Center for Microbial Lipids, School of Agriculture Engineering and Food Science, \\ Shandong University of Technology, Zibo 255049, Shandong, PR. China
}

Article history

Received: 03-08-2016

Revised: 23-11-2016

Accepted: 30-01-2017

Corresponding Author:

Imran Pasha

National Institute of Food

Science and Technology,

University of Agriculture

Faisalabad, 38000, Pakistan

Tel: 92-41-9200853,

Fax: +92-41-92001439

Email: ipasha2001@uaf.edu.pk

And

Yuanda Song

Colin Ratledge Center for Microbial Lipids, School of Agriculture Engineering and Food Science, Shandong University of Technology, Zibo 255049, Shandong, PR. China Email: ysong@sdut.edu.cn

\begin{abstract}
The aim of this study is to evaluate nutritional value of selected commonly consumed fresh water fish species of Pakistan. Proximate composition and fatty acids profile of mostly consumed fresh water fish species of Pakistan namely Balm or Baam (Anguilla anguilla), Sole (Channa marulius), Damra (Labeo rohita) and Malhi (Wallago atto) were analysed. Proximate composition data showed a significant difference $(p<0.05)$ among the nutritional components except carbohydrate and gross energy contents. Protein and moisture contents found plenteous in the Baam (Anguilla anguilla) whereas ash and fat contents in Malhi (Wallagoatto) are found copious. Saturated Fatty Acids (SFAs) and Monounsaturated Fatty Acids (MUFAs) found to be principal Fatty Acids (FAs) with their ranges from (48.43 to $65.76 \%)$ and $(25.72$ to $31.37 \%)$ respectively. In SFAs and MUFAs, palmitic acid (32.4 to 47.71\%) and oleic acid (10.97 to $21.26 \%$ ) were identified as major FAs respectively in all species. The existence of short and medium chain SFAs is advantageous for designation of these fish species as alterative diet as these above mentioned FAs not only involved in metabolic regulation but also helpful to remove the metabolic disparities related to Coronary Heart Diseases (CHD), brain seizure, Alzheimer disease, glucose homeostasis, appetite and gastric acid secretion. Among the PUFAs, Omega-6 PUFAs are found to be more abundant than Omega-3 with Linoleic acid (LA, C18:2ஸ6) as predominant PUFA in A. anguilla $(9.137 \%)$ and L. rohita $(9.128 \%)$ and $\gamma-$ linolenic acid (GLA, C18:3ஸ́6) and cis-8, 11, 14 Eicosatrienoic (hGLA, C20:3 $\omega 6)$ as most prevailing PUFAs in C. marulius $(2.3 \%)$ and $W$. atto $(1.61 \%)$ respectively. These species found to be a substantial source of Omega-6 PUFAs with $\omega 3 / \omega 6$ ratio less than 1 . The overall all summation of Eicosapentaenoic (EPA, C20:5 $\omega 3$ ) acid and Docosahexaenoic acid (DHA, C22:6 $\omega 3$ ) ranged from $0.38 \%$ in C. marulius to $1.93 \%$ in L. rohita.
\end{abstract}

Keywords: Bioactive Components, Fatty Acids Profiling, Nutrition of Fresh Water Fishspecies

\section{Introduction}

There are, in Pakistan, reportedly 531 species of fish out of which 233 are of fresh water fish species (Saify et al., 2000). A large variety of fresh water fish species are cultured commercially in Pakistan. The area which is used for the fish farming system is about 60,500 ha. The fresh water fishes that are mostly cultured and consumed in Pakistan are Damra (Labeo Rohita), Sole (Channamarulius), Catla (Catla Catla), Baam or Balm
(Anguilla anguilla), Brown trout (Salmotrutta), Rainbow trout (Oncorhynchusmykiss), Malhi (Wallagoatto), Marigal (Cirrhinusmrigala), Grass carp (Ctenopharyngodonidella) and Silver carp (Hypophthalmichthysmolitrix) etc. (Saify et al., 2000). Fish is also an important source of superior kind protein, essential minerals and vitamins. But the most important feature of fish carcass is its oil which is the origin of unparalleled and ample source of Omega-3 ( $\omega 3$ ) and Omega-6 ( $\omega 6)$ long chain polyunsaturated fatty acids 
(LC-PUFAs). These PUFAs have a lot of health significances, especially as, precursors of prostaglandins which govern many activities such as blood clotting, inflammation and preserving the wholeness of tissue layer of all living cells. The absorption of fat soluble vitamins $\mathrm{K}, \mathrm{E}, \mathrm{A}$ and $\mathrm{D}$ from the diet and metabolism of cholesterol of body is also regulated by the PUFAs (Connor, 2000). A lot of PUFAs are present in the carcasses of these fresh water fishes like docosahexaenoic (DHA, C22:6 $\omega 3$ ), eicosapentaenoic (EPA, C20:5 $\omega^{3}$ ) and arachidonic acid (C20:4 $\omega 6$ ), these PUFAs are not formed by the human body but their involvement in body metabolism is very crucial (Kolanowski and Laufenberg, 2006; Holub and Holub, 2004; Glogowski and Ciereszko, 2001). The composition of fresh water fish species and marine water fish species may vary due to their different feeding habits and ecological factors (Rahnan et al., 1995). Fish consumption is very important for health as it also contain many essential amino acids in large quantity peculiarly Lysine which deficient in pulses and cereals (Glogowski and Ciereszko, 2001). Fish usage should be enhanced to accompaniment the pattern of amino acids and to increase the quality of intake protein (Holub and Holub, 2004). Some omega-3 and Omega-6 PUFAs are reputed as Essential FAs (EFAs). These EFAs have crucial role in the preventing and intervention of wide kind of disparities like breast cancer, inflammatory illnesses, osteoporosis, atherosclerosis, hypertriglyceridemia, autoimmune, hypertension, embolic phenomena, thrombosis and rheumatoid arthritis (Uauy and Valenzuela, 2000).

Pakistan has growing population with low availability of quality protein and handiness of per capita protein is much underneath the lower limit of daily necessities. The livestock sector alone does not have enough capacities to cope with the rising demands of population of human being (Chaudhry, 2008). Fish is a trashier and splendid source of animal protein, therefore increase in the consumption of fish oil and fish meat can help us to bring together the EFAs and protein gap and may bring the multifaceted economical benefits and nutritional significance (Waseem, 2007). Owing to the crucial dietetic and medical role of these fatty acids in human health, it is very important to have awareness of the composition profile of the vast fatty acids for mostly consumed fish species Baam (Anguilla Anguilla), Sole (Channamarulius), Damra (Labeo Rohita) and Malhi (Wallagoatto). So the objective of this work is to look into visibility of fatty acids and composition in ordinarily ingested fish species, A. anguilla, C. marulius, L rohita and $W$. atto, that were selected on the basis of consumption pattern, prime economic importance, fast growing nature, taste, savor, sturdy and resistant nature towards various ecological conditions. From the last twenty years, there is an extension in the consciousness of people of getting health attains from the usage of fish oil (Lovegrove et al., 1997), because this oil have revealed a richest source of Omega-3 and Omega-6 LCPUFAs peculiarly docosahexaenoic (DHA) and eicosapentaenoic (EPA). Since human beings are incapable of synthesizing these Fatty Acids (FAs) with double bond in $\omega 6$ and $\omega 3$ places so their involvement in the body is very crucial but fish can prepare these PUFAs by ingesting on microalga or bacteria (Simopoulos, 2002). The fat quantity and composition of fatty acids diverges according to various factors like reproductive cycle period, size, fishing season, sex and geographical location (Luzia et al., 2003).

Owing to uprising requirement for LC-PUFAs, it is worthy to personate the novel origins from disposed byproducts of the fish industry not only to maximize the gainfulness of disposed by-products of the fishing products but also to discover new worthful origins of prime quality of LC-PUFAs oil and to avert the overhunting of common fish species (Jayasinghe et al., 2003). The reason behind the prime importance and significance given to LC-PUFAs is that it is useful to prevent the cardiac disorders (Connor, 2000; Simopoulos, 2002; Kinsella, 1998; Mozaffarian et al., 2005), disorders of brain growth and retina functioning (Crawford, 1993) and also lower the chances of multiple inflammation, psoriasis and scelerosis (Kinsella, 1998; Goodnight et al., 1982).

Marine fish species contain impressive amount of LC-PUFAs particularly DHA (docosahexaenoic acid, C22:6 $\omega 3$ ) and EPA (eicosapentaenoic acid, C20:5 ́́3) (Ackman, 1999). The dietitians commonly recommend that for infants the daily intake of $0.5 \mathrm{~g}$ EPA/DHA whereas coronary heart patients and normal adults should take an average uptake of $1 \mathrm{~g}$ /day (Kris-Etherton et al., 2003). According to investigators fresh water fish species contain lower quantity of Omega-3 than the marine fish species (Rahnan et al., 1995). Marine fish species possess a high proportion of total $\omega 3 / \omega 6$ fatty acids deviating from 5 to 10 or more which is much more eminent for sea fish species than for freshwater fish species. According to work done by (Simopoulos, 2002) ratio of $\omega 6 / \omega ́ 3$ less than $3 / 1$ has restrictive effects on many diseases, including cancer cardiovascular, inflammatory and autoimmune diseases and the summation of $\dot{\omega}-3$ PUFA could forbid diseases and can ameliorate nutritionary value (Moreira et al., 2001). But it is very hard to find out the optimal $\omega 6 / \omega 3$ ratio as most of fatal and chronic diseases are multigenic and multifactorial (Simopoulos, 2002).

Up to best of our knowledge, no study has been published yet about the nutritional quality assessments of market available three fish species namely $W$. atto, $C$. marulius and A. Anguilla. So keeping in all above, it is 
very crucial to investigate and explore the nutritional value of local most commonly consumed fish species of Pakistan. As food processing sector is among the top growing sector and in the food manufacturing sector, dairy and meat processing industry is the most flourishing industry. Therefore this work may provide useful information for its applications in pharmaceutical products healthcare, food, neutraceutical and as constituents in feed, aquaculture and agricultural industry.

\section{Materials and Methods}

\section{Raw Material Procurement, Dissection and Preservation}

The fish samples were collected from reliable fisherman in local Fish market namely Jhang Bazar Lyallpur. The samples of each fish species Balm ( $A$. anguilla), Sole (C. marulius), Damra (L. rohita) and Malhi ( $W$. atto) were gathered on ice. Every Fish was stored at $-20^{\circ} \mathrm{C}$ in sterilized polythene bags after dissecting, skinning and filleting. All the solvents and chemicals used were of analytical grade.

\section{Fish Composition}

The moisture, Crude Protein, Crude Fat and Ash contents were determined following the Horwitz (2006) method. Whereas Total carbohydrates were estimated by deducting the summation of \% Crude Protein (CP) \% fat (F) and \% ash contents (A) from 100 (Onyeike et al., 2000) by using the following equation:

$$
\% \text { Total carbohydrates }=100-(F+C P+A)
$$

\section{Estimation of Gross Energy Value (Caloric value)}

The percentages of Fat (F) Crude Protein (CP) and Carbohyderate $(C)$ were found and multiplied by their respective caloric energy values i.e., 9, 4 and $4 \mathrm{Kcal}$ in $100 \mathrm{~g}$ of Fish sample (Farhat and Shakoor, 2011) to find the caloric value of each species as shown below:

$$
\text { Caloric value }=(4 C P+9 F+4 C) / 100 g \text { weight }
$$

\section{Fatty Acid Analysis}

\section{Extraction of Fat}

The fish fat was extracted from $2.5 \mathrm{~g}$ small pieces of fish meat by few modifications in the method utilized by Bligh and Dyer (Sargent et al., 1995; Citil et al., 2014). Different parts of fish were individually minced and homogenized using a homogenizer. The meat samples were impregnated with $12.5 \mathrm{~mL}$ of chloroform/methanol/distilled water $(2: 2: 1)$ comprising $0.01 \%$ butylated hydroxyl toluene. Organic liquid phase was incurred after mixed-phase separation. The liquid was passed through Whatman No. 1 filter paper and dried with moderate anhydrous sodium sulfate, then concentrated by using an evaporation-condensation rotating apparatus in a $40^{\circ} \mathrm{C}$ water bath. Total lipid content was gravimetrically quantified.

\section{Fatty Acid Derivatisation}

Fatty acids were determined and derivatised from samples (fat of each fish species) based on the method of Farhat and Shakoor (2011) with slight modifications. About $40 \mathrm{~mL}$ of methanol were taken in $50 \mathrm{~mL}$ conical flask. It was placed on ice water and then $10 \mathrm{~mL}$ of sulphuric acid were added and this solution was saved for further use. Methylation of fatty acids in the oils was carried out according to the procedure described by (Cocks and Rede, 1966) with some modifications as follows. About $200 \mathrm{mg}(0.21 \mathrm{~mL})$ oil was taken in a 50 $\mathrm{mL}$ screw capped Pyrex glass tubes having $50 \mathrm{~cm}$ length and $1 \mathrm{~cm}$ internal diameter. Then $2 \mathrm{~mL}$ of methanolic sulphuric acid was added into each tube and glass vials were put in a pre-heated oven at $80^{\circ} \mathrm{C}$ for 1 $\mathrm{h}$ and shake for $15 \mathrm{~min}$. The glass vials were taken out cooled and $2 \mathrm{~mL}$ of distilled water were added into each tube to stop the reaction. Then esterified fatty acids (Fatty Acid Methyl Esters, FAME) were extracted with $1 \mathrm{~mL}$ of petroleum ether $\left(40-60^{\circ} \mathrm{C}\right)$ thrice. After that the ether content was evaporated and remaining oily surface was injected into gas chromatography for fatty acid profile analysis.

\section{Gas Chromatography (GC)}

The FAME samples of each fish species was examined by Gas Chromatography by using Helium as a carrier gas and SGE forte BPX 70 column (30 $\mathrm{m} \times 0.25 \mathrm{mmID} \times 0.25 \mu \mathrm{m}$ film thicknesses $)$. The initial temperature of the column was set and held at $50^{\circ} \mathrm{C}$ for $1 \mathrm{~min}$. The temperature was then raised at $2{ }^{\circ} \mathrm{C} / \mathrm{min}$ to $188^{\circ} \mathrm{C}$ which was held for $10 \mathrm{~min}$ followed by an increase at the same rate to $240^{\circ} \mathrm{C}$ where it was held for $4 \mathrm{~min}$ and then returned to the initial temperature. The extraneous combined FAME standard will be used to discover and identify the peaks. Fatty acids was measured by equating their peaks with the relevant peak areas of the corresponding standard fatty acids where each fatty acid was then stated as a percentage of the total fatty acids measured (Farhat and Shakoor, 2011).

\section{Statistical Analysis}

The data obtained for each parameter was subjected to statistical analysis using Minitab statistical package (Minitab Inc, 2012). The level of significance was determined by applying analysis of variance technique (one factor and two factor factorial CRD). Significant 
ranges were further postulated using DMR mean comparison test (Steel et al., 1997). Each experiment was performed triple times.

\section{Results and Discussion}

The present investigation was contrived to measure various physiochemical characteristics, composition and fatty acids mapping in commonly consumed selected fresh water fish species. Especially quality and quantity of fish oil extracted from these fishes was checked with special reference to Saturated Fatty Acids (SFAs), Monounsaturated Fatty Acids (MUFAs), Essential Fatty Acids and Polyunsaturated Fatty Acids (PUFAs) like Omega-3 and Omega-6 and their fraction in the samples.

\section{Fish Composition}

To find out the nutritional and compositional values of our selected fish species, we analyzed the moisture, fat, crude protein, ash and carbohydrate contents of these fish species. The results showed (Table 1) that the moisture contents of the fish differed from species to species significantly $(\mathrm{p}<0.05)$. The highest moisture (78.233\%) was observed in A. anguilla and the least amount of moisture $(73.933 \%)$ was observed in the $C$. marulius. Micro flora is best flourished at higher moisture levels. Oxidation of meat products is another issue related with moisture contents. Lower moisture contents are required to achieve a sustained shelf life in these types of products. It is reported that the increase in fat level in fish species decrease moisture content (Ayo et al., 2007). Similar findings were observed by (O'Brien, 2004) and (Ashraf et al., 2011) in lake, pond water and marine shallow water fish species which exhibit 73.46 to $79.6 \%$ moisture contents.

Fish species are the excellent sources of superior quality protein and possess high amounts of essential and functional amino acids amino acids which regulate and take part in various metabolic pathways and with beneficial health effects on growth, survival, development, lactation and development of an organism (Wu, 2010). Proline, glycine, methionine, tyrosine, cystine, leucine, arginine, glutamic acid, aspartate, taurine and tryptophan, have been sorted out as functional amino acid in human nutrition. Furthermore, amino acids bring crucial functions in cell signaling and act as regulators of gene expression and protein phosphorylation cascade $(\mathrm{Wu}, 2013)$. The protein from the fish sources contains many kinds of essential and functional amino acids which are beneficial to human health. The range of protein level in the four species was from 49.61 to $53.97 \%$, with $49.61,50.19,53.61$ and
$53.97 \%$ in C. marulius, W. atto, L. rohita and A. anguilla respectively. These results are in accord with previous finding reported by (Maurizio et al., 2010) according to which protein contents of most species of fresh nature contain protein from 42.4 to $51.5 \%$. Luzia et al. (2003) also showed that protein contents also varied according to the location of fish caught.

Fat is a beneficial reservoir of vitality as it furnishes almost double energy (i.e., $9 \mathrm{kcal} / \mathrm{gm}$ ) of the carbohydrates. Fat contents of four species (Table 1) differ significantly among four species. The fat contents are in the order of $11.83,11.43,10.6$ and $10 \%$ for $W$. atto, C. marulius, L. rohita and $A$. anguilla respectively. It was observed that deep water fish species have high contents of fat than shallow water fish species due to availability of better quality and variety of feed. The variation in fat contents may arise due to Lipoxygenases which is major problem in post mortem fish species and enzymatic hydrolysis of lipid (Wedoud et al., 2011). Wedoud et al. (2011) investigated the fat percentage in the marine fish species of Mauritius in different seasons and concluded that fish species caught in January and September possess high contents of fat (8.4 to $13 \%)$ which are the reproductive months of fish species. The ash contents from fish muscles are indicator of minerals contents as fish may also have many essential and trace minerals. Specie $W$. atto was found to be at top with highest ash contents $(8.45 \%)$ followed by $C$. marulius (7.63\%), A. anguilla $(6.93 \%)$ and L. rohita $(6.35 \%)$. These results were almost same as the findings of (Yesim and Fatih, 2007) who reported the ash content are in the range of 6.5 to $12.05 \%$ in the commercially important fresh water fish species of Turkey. Carbohydrates are the sources of energy with status "Ready" in the body and 1 gram consumption of carbohydrates supplies 4Kcal energy. The highest carbohydrate was found in Channamarulius (31.40\%) and most dispirited amount of carbohydrates was found in Anguilla anguilla (26.44\%). These results are in accord with the result of (Osman et al., 2001) who found the carbohydrates in fresh water species fall between 17.8 to $37.4 \%$. As fish is a rich source of protein, carbohydrates and fat, it is not only heath beneficial but a plenteous source of energy. So total energy from these nutritive components is the gross energy value which is rough estimation of energy we get from the consumption of fish. Fish species did not differ significantly with respect to gross energy value. It showed that energy values do not vary much to one another and only a negligible difference was found which ranges from 429.56 to $434.56 \%$. Our findings are in accord with the results of (Zygmunt et al., 2012) according to which the energy values from the consumption of fish varies from 428.7 to $437.5 \mathrm{Kcal} / 100 \mathrm{~g}$. 
Ahsan Hameed et al. / American Journal of Biochemistry and Biotechnology 2017, 13 (1): 15.26 DOI: 10.3844/ajbbsp.2017.15.26

Table 1. Chemical composition of muscles from selected commonly consumed fresh water fish species of Pakistan

\begin{tabular}{lllll}
\hline Name of analysis & Malhi (Wallagoatto) & Sole (Channamarulius) & Damra (Labeorohita) & Baam (Anguilla anguilla) \\
\hline Total moisture (\%) & $75.03 \pm 3 \mathrm{bc}$ & $73.93 \pm 3.69 \mathrm{c}$ & $77.21 \pm 4.63 \mathrm{ab}$ & $78.23 \pm 5.47 \mathrm{a}$ \\
Crude protein (\%) & $50.19 \pm 1.91 \mathrm{~b}$ & $49.61 \pm 2.93 \mathrm{c}$ & $53.61 \pm 1.20 \mathrm{a}$ & $53.97 \pm 0.46 \mathrm{a}$ \\
Crude fat (\%) & $11.83 \pm 0.47 \mathrm{a}$ & $11.43 \pm 0.57 \mathrm{ab}$ & $10.60 \pm 0.63 \mathrm{bc}$ & $10.00 \pm 0.7 \mathrm{c}$ \\
Ash contents (\%) & $8.45 \pm 0.50 \mathrm{a}$ & $7.63 \pm 1.04 \mathrm{c}$ & $6.35 \pm 1.04 \mathrm{c}$ & $6.93 \pm 1.66 \mathrm{c}$ \\
Total carbohydrates $(\%)$ & $27.92 \pm 1.11 \mathrm{~b}$ & $31.40 \pm 1.57 \mathrm{a}$ & $28.64 \pm 1.71 \mathrm{ab}$ & $26.44 \pm 1.85 \mathrm{~b}$ \\
Gross energy (Kcal/100g) & $429.56 \pm 17.18 \mathrm{a}$ & $432.75 \pm 21.63 \mathrm{a}$ & $434.88 \pm 26.09 \mathrm{a}$ & $430.74 \pm 30.51 \mathrm{a}$ \\
\hline
\end{tabular}

*Means sharing similar letters are statistically non-significant

Table 2. Fatty acids profile of fish species from selected commonly consumed fresh water fish species of Pakistan

\begin{tabular}{|c|c|c|c|c|}
\hline FAMEs & Malh (W.atto) & Sole (C marulius) & Damra (L. rohita) & $\operatorname{Baam}$ (A. anguila) \\
\hline C8:0, Caprylic acid & $0.278_{\mathrm{a}}$ & $0.171_{\mathrm{c}}$ & $0.247_{\mathrm{b}}$ & $0.165_{\mathrm{c}}$ \\
\hline C10:0, Capric acid & $0.011_{\mathrm{a}}$ & $0.005_{\mathrm{b}}$ & $0.000_{\mathrm{c}}$ & $0.000_{\mathrm{c}}$ \\
\hline C12:0, Lauric Acid & $0.575_{\mathrm{a}}$ & $0.094_{c}$ & $0.184_{b}$ & $0.082_{\mathrm{c}}$ \\
\hline C13:0, Tridecanoate acid & $0.854_{\mathrm{a}}$ & $0.043_{\mathrm{c}}$ & $0.549_{\mathrm{b}}$ & $0.500_{\mathrm{b}}$ \\
\hline C14:0, Myristic acid & $3.487_{\mathrm{b}}$ & $2.766_{\mathrm{c}}$ & $3.781_{\mathrm{a}}$ & $2.568_{\mathrm{c}}$ \\
\hline C15:0, Pentadecanoic acid & $1.867 \mathrm{a}$ & $1.750_{\mathrm{ab}}$ & $1.640_{\mathrm{b}}^{\mathrm{a}}$ & $1.197_{\mathrm{c}}$ \\
\hline C16:0, Palmitic acid & $35.050_{\mathrm{b}}$ & $47.710_{\mathrm{a}}$ & $32.410_{\mathrm{b}}$ & $32.400_{\mathrm{b}}$ \\
\hline C17:0, Heptadecanoic acid & $4.435_{\mathrm{a}}$ & $2.585_{\mathrm{c}}$ & $3.038_{\mathrm{b}}$ & $1.572_{\mathrm{d}}$ \\
\hline $\mathrm{C} 18: 0$, Stearic acid & $10.487_{\mathrm{a}}$ & $9.403_{b}$ & $7.977_{\mathrm{c}}$ & $8.416_{\mathrm{c}}$ \\
\hline C20:0, Arachidic acid & $0.232_{\mathrm{c}}$ & $0.308_{\mathrm{b}}$ & $0.632_{\mathrm{a}}$ & $0.170_{\mathrm{d}}$ \\
\hline C22:0, Behenic acid & $0.327_{\mathrm{c}}$ & $0.437_{\mathrm{b}}$ & $0.860_{\mathrm{a}}$ & $0.483_{\mathrm{b}}$ \\
\hline C23:0 Tricosanoic & $0.61_{\mathrm{a}}$ & $0.18_{\mathrm{a}}$ & $0.72_{\mathrm{a}}$ & $0.86_{\mathrm{a}}$ \\
\hline C24:0 Lignoceric & $0.64_{\mathrm{a}}$ & $0.31_{\mathrm{a}}$ & $0.18_{\mathrm{a}}$ & $0.12_{\mathrm{a}}$ \\
\hline$\sum \mathrm{SFA}$ & 58.86 & 65.76 & 52.21 & 48.43 \\
\hline C14:1, Myristoleic acid & $0.656_{\mathrm{c}}$ & $0.863_{\mathrm{b}}$ & $1.452_{\mathrm{a}}$ & $0.445_{\mathrm{d}}$ \\
\hline C15:1, cis-10 pentadeca acid & $0.885_{\mathrm{a}}$ & $0.330_{\mathrm{c}}$ & $0.587_{\mathrm{b}}$ & $0.359_{\mathrm{c}}$ \\
\hline C16:1, Palmitoleic acid & $6.787_{\mathrm{bc}}$ & $6.114_{c}$ & $10.787_{\mathrm{a}}$ & $7.883_{\mathrm{b}}$ \\
\hline C17:1, cis-10 Heptadeca acid & $0.920_{\mathrm{a}}$ & $0.597_{\mathrm{c}}$ & $0.743_{\mathrm{b}}$ & $0.685_{\mathrm{b}}$ \\
\hline C18:1, Elaidic acid & $0.186_{\mathrm{c}}$ & $0.885_{\mathrm{a}}$ & $0.411_{\mathrm{b}}$ & $0.244_{c}$ \\
\hline C18:1, Oleic acid & $21.260_{\mathrm{a}}$ & $11.950_{\mathrm{c}}$ & $10.970_{\mathrm{c}}$ & $17.860_{\mathrm{b}}$ \\
\hline C20:1, cis-11 Eicosenoic acid & $0.512_{\mathrm{b}}$ & $4.097_{\mathrm{a}}$ & $0.503_{\mathrm{b}}$ & $0.339_{\mathrm{c}}$ \\
\hline C22:1, Erucic Acid & $0.164_{d}$ & $0.961_{\mathrm{a}}$ & $0.274_{b}$ & $0.228_{\mathrm{c}}$ \\
\hline$\sum$ MUFAs & 31.37 & 25.79 & 25.727 & 28.048 \\
\hline C18:2, Linoleic acid (LA) ( $\omega 6)$ & $0.213_{\mathrm{b}}$ & $0.166_{b}$ & $9.128_{\mathrm{a}}$ & $9.137_{\mathrm{a}}$ \\
\hline C18:3, $\gamma$-linolenic acid (GLA) ( $\omega 6)$ & $1.387_{\mathrm{d}}$ & $2.300_{\mathrm{c}}$ & $6.947_{\mathrm{a}}$ & $4.845_{\mathrm{b}}$ \\
\hline C18:3, $\alpha$-linolenic acid $(\omega 3)$ & $1.187_{\mathrm{c}}$ & $2.08_{\mathrm{a}}$ & $0.573_{\mathrm{d}}$ & $1.772_{\mathrm{b}}$ \\
\hline C20:3 cis-8, 11, 14 Eicosatrienoic (hGLA) (ஸ́6) & $1.61_{\mathrm{a}}$ & $1.2_{\mathrm{a}}$ & $1.84_{\mathrm{a}}$ & $1.98_{\mathrm{a}}$ \\
\hline C20:3 cis-11,14,17 Eicosatrienoic $(\hat{\omega} 3)$ & $0.93_{\mathrm{a}}$ & $0.51_{\mathrm{a}}$ & $0.61_{\mathrm{a}}$ & $1.23_{\mathrm{a}}$ \\
\hline C20:4, Arachidonic acid (ஸ́6) & $0.481_{\mathrm{a}}$ & $0.223_{\mathrm{c}}$ & $0.402_{b}$ & $0.472_{\mathrm{a}}$ \\
\hline C20:5, Eicosapentaenoic acid (EPA) (ஸ́3) & $0.414_{c}$ & $0.353_{\mathrm{d}}$ & $0.693_{\mathrm{a}}$ & $0.461_{\mathrm{b}}$ \\
\hline C22:5 Docosapentanoic (DPA) $(\omega 3)$ & $0.81_{\mathrm{a}}$ & $0.68_{\mathrm{a}}$ & $0.84_{a}$ & $0.96_{\mathrm{ab}}$ \\
\hline C22:2 cis 13,16 Docosadienoic $(\omega 6)$ & $0.41_{\mathrm{a}}$ & $0.19_{\mathrm{a}}$ & $0.34_{\mathrm{a}}$ & $0.44_{\mathrm{a}}$ \\
\hline C22:6, Docosahexaenoic acid (DHA) (ஸ́3) & $0.37_{\mathrm{b}}$ & $0.110_{\mathrm{c}}$ & $1.242_{\mathrm{a}}$ & $1.294_{\mathrm{a}}$ \\
\hline$\sum$ PUFAS & 7.81 & 7.812 & 22.615 & 22.591 \\
\hline$\omega 3$ & 3.71 & 3.73 & 3.96 & 5.72 \\
\hline$\omega 6$ & 4.1 & 4.08 & 18.66 & 16.87 \\
\hline$\omega 3 / \omega 6$ & 0.9 & 0.92 & 0.21 & 0.34 \\
\hline$\omega 6 / \omega 3$ & 1.11 & 1.09 & 4.71 & 2.95 \\
\hline EPA & 0.39 & 0.31 & 0.693 & 0.461 \\
\hline DHA & 0.37 & 0.07 & 1.242 & 1.294 \\
\hline EPA+DHA & 0.76 & 0.38 & 1.935 & 1.755 \\
\hline EPA/DHA & 1.05 & 4.43 & 0.56 & 0.36 \\
\hline
\end{tabular}

*Means sharing similar letters are statistically non-significant

\section{Fatty Acids Profile}

Thirty one fatty acids in $W$. atto and $C$. marulius and thirty fatty acids in $L$. rohita and $A$. anguilla were identified and evaluated in this study. Table 2 showed the percentages as mean value of fatty acids for four species. Relation of Individual lipid class with the total lipids contents was analyzed in this study. Unlike the 
findings of (Zhang et al., 2014) SFAs found to be have a positive relation with total Lipid contents and PUFAs have a reverse association with the total lipid contents. Our findings are in agreement with the work of (Belling et al., 1997). Dominancy of SFAs was found over the MUFAs and PUFAs. The results showed that SFAs from C8:0 to C24:0 existed among the fish species. The detected range of SFAs in selected species was from $48.43 \%$ in $A$. anguilla to $65.76 \%$ in $C$. marulius. The key identified SFAs were palmitic acid (C16:0), stearic acid (C18:0) and myristic acid (C14:0). A low amount of median chain FAs, ranged from 0.278 to $0.165 \%$ was found in these fishes, with caprylic acid (C8:0) as the major one which was plenteous in the $W$. atto $(0.278 \%)$ and gloomiest in the A. anguilla $(0.165 \%)$. The inclusion of caprylic acid in diet is crucial for lessen the amount of unacylatedgherlin, an orexigenic peptide hormone, as acylatedgherlin involves in regulation of growth hormones, gastric acid secretion, appetite, homeostasis of glucose and adiposity (Lemarié et al., 2015). The A. anguilla and L. rohita were devoid of capric acid or decanoic acid (C10:0) while it was existed with trace amounts in $W$. atto $(0.011 \%)$ followed by $C$. marulius (0.05\%). Decanoic acid, an essential component of therapeutic diets, have recently showed an effectual control over brain seizure and delaying in picrotoxin-induced seizures in brain (Chang et al., 2015) Lauric (C12:0) and trideanoate acid (C13:0) were also plenteous in the $W$. atto and deficient in C. marulius. Short chain and medium chain SFAs (C: 6C: 12) metabolized rapidly in body as compared to long chain SFAs. This ease of metabolism of short chain SFAs is due to free and rapid transportation of short SFAs across mitochondrial membranes in liver (Dayrit, 2015). Short chain SFAs also ascertained to minify the cholesterol degree of plasma and consequently letting down the peril of Coronary Heart Diseases (CHD) (Legrand et al., 2010). Myristic acid (C14:0) showed different trend as it was more abundant in L. rohita $(3.781 \%)$ and least amount was found in A. anguilla (2.568\%) with 3.487 and $2.766 \%$ in $W$. atto and C. marulius respectively. A recent study conducted by (Noto et al., 2015) amazingly revealed that $\mathrm{C} 14$ is involved in lowering of plasma level of HDL-C (High density lipoproteins carrying cholesterol to liver for metabolism) by trapping them in cell surface HSPG (heparan sulfate proteoglycan).

The amount of long chain SFAs from pentadecanoic acid (C15:0) tolignoceric (C24:0) were also significantly different among the four fresh water fish species. The results showed that highest amount of pentadecanoic acid (C15:0) was detected in $W$. atto $(1.867 \%)$ and least amount of it found in $A$. anguilla $(1.197 \%)$. Surplus palmitc acids $(\mathrm{C} 16: 0)$ was found in $C$. marulius (47.710\%) followed by $W$. atto $(35.050 \%)$ and almost equally distributed in $A$. anguilla and L. Rohita So it was the most abundant fatty acid among SFAs. Heptadecanoic acid $(\mathrm{C} 17: 0)$ is copious in $W$. atto $(4.435 \%)$ and L. Rohita (3.038\%) followed by $C$. marulius $(2.585 \%)$ and $A$. anguilla (1.572\%). Like PUFAs, odd chain SFAs (specifically C15:0 and C17:0) are found to enhance the membrane fluidity and consequently decrease the risk of various type scleroses (Jenkins et al., 2015). Fonteh et al. (2015) also concluded that Alzheimer disease stricken people have low tissue level of $\mathrm{C} 15: 0$ and $\mathrm{C} 17: 0$. These odd chain SFAs also showed reverse relation with carcinogenic influence and CHD occurrence (Jenkins et al., 2015). Stearic acid (C18:00) was the second most abundant SFA found in the lipids of these fish species. $W$. attois characterized with highest stearic acid quantity with $10.487 \%$ followed by $9.403,8.416$ and $7.977 \%$ in $C$. marulius, A. anguilla and L. rohita respectively. Like short chain SFAs, very long chains SFAs (C20-C24) were also detected in fractional quantity. The detected very long chain SFAs were arachidic acid (C20:0), behenic acid, (C22:0), tricosanoic acid (C23:0) and lignoceric acid (C24:0). So among the thirteen detected SFAs, palmitic (C16:0), stearic (C18:0) and myristic (C14:0) acids were the major SFAs. These findings are in accord with the findings of Guil-Guerrero et al. (2011), High prevailing quantity of SFAs may be due to less efficiency of fish species in utilizing the SFAs as core energy source which resulted in the rise of SFAs (Nath and Banerjee, 2012). Regost et al. (2003) stated that De novo synthesis and diets are the two sources of fatty acids in muscles. If the fish feed mostly on the diet mainly insects and other aquatic then the saturated fatty acids contents rises and if they feed on the plant and algae sources then it contain mostly unsaturated fatty acids. So the fluctuation in the fatty acids is due to the continual recycling of Fatty acids in food web, habitat and feed.

Eight MUFAs were identified during analysis, ranged from $25.7 \%$ in L. rohita to $31.3 \%$ in $W$. atto, with aberrant association with total lipid contents. Results (Table 2) showed that myristoleic acid (C14:1), a promising anti-prostatic cancer therapeutic FA in future (Iguchi et al., 2001), was chiefly detected in L. rohita (1.452\%) whereas. Palmtoleic acid (C16:1), second key detected MUFA in all fish species, but predominantly detected in L. rohita $(10.78 \%)$. Epidemiological reports disclosed that $\mathrm{C} 16: 1$ involves in hemostasis, cholesterol metabolism and insulin sensitivity, lower risk of diabetes, lower levels of inflammation with net mixed effects on serum lipid and CVD (higher HDL, lower LDL, lower fibrinogen, but higher triglycerides and greater insulin resistance) (Bernstein et al., 2014). Overall effects of Palmtoleic acid are still a parable and largely depend on its origin and area of action (De 
Fabiani, 2011). The major abundant MUFA in all fish species was oleic acid (C18:1). W. atto (21.26\%) contained higher amount of oleic acid than other selected fish species. Oleic acid comprised almost $60-80 \%$ of the collective MUFAs. Whereas eicosenoic acid (C20:1) and erucic acid (C22:1) was preponderantly found in $C$. marulius. These results are in accord with the results of Luzia et al. (2003), according to which the contents of MUFAs ranges from $23-33 \%$ in the fresh water fish species. All the spotted MUFAs were of "cis nature" and these cis MUFAs are regarded as with neutral effects on the LDL-cholesterol level in serum (Ros, 2013). Generally vegetable oil especially canola and virgin olive oil has been considered as MUFAs rich sources. Substitution of MUFAs in diet (rather than carbohydrates$\mathrm{CHO}$ and SFAs) has unveiled even more betterment in insulin sensitivity, $\beta$-cells activity, glycemic regulation, HDL-Cholesterol level preservation, body weight maintenance and avoidance of CVD threats (Gillingham et al., 2011). So one can accomplish the above revealed health attains by consuming the under study fish species as these species contained handsome and appropriate proportion of MUFAs.

The polyunsaturated fatty acids are those fatty acids that contain more than one double bond in the carbon chain. In this study, total ten PUFAs were identified in the oil of four species. The analysis of variance showed that highly significant difference $(\mathrm{p}<0.05)$ existed among the PUFAs except cis-8, 11, 14 Eicosatrienoic (C20:3), cis-11,14,17 Eicosatrienoicacid (C20:3) and cis 13,16 Docosadienoic (C22:2). Total PUFAs varied from $7.8 \%$ (W. atto) to $22.61 \%$ (L. rohita) with $\gamma$-linolenic acid

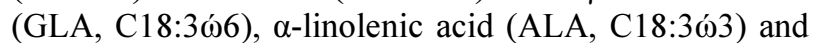
cis-8, 11, 14 Eicosatrienoic (hGLA, C20:3ஸ́6)as prevalent FAs in $W$. atto and $C$. marulius and Linoleic

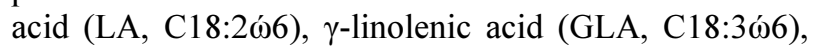
cis-8, 11, 14 Eicosatrienoic (hGLA, C20:3ம6), Docosahexaenoic acid (DHA, C22:66́3) in L. rohita and A. anguilla respectively. This divergence arose among these species due to various factors such as state of their reproductive cycle, organ source, habitat, size, season and sex (Regost et al., 2003). Table 2, showed the amount of PUFAs present in the oil of four species. Equal number of omega- 6 and omega 3 PUFAs had been traced but quantitatively the contribution of omega- 6 was found to be more than the omega-3 which is characteristic of fresh water fish species. Among the $\omega 6$ PUFAs, Linoleic Acid (LA) (C18:2) and $\gamma$-linolenic acid (C18:3) (GLA) were principally detected respectively whereas cis 13, 16 Docosadienoic acid (C22:2) ascertained to be in tiniest amount.

Among theó3-PUFAs, ALA was the most amplefatty acid in all fish species followed by cis-11,14,17 Eicosatrienoic, DHA, DPA and EPA and among $\omega 6$ PUFAs, GLA was the most plentiful followed by hGLA and AA.LA and GLA followed the same trend as up to 9 and $4-7 \%$ LA and GLA were detected in A. anguilla and L. rohita respectively. ALA, which is believed to have healthy effects on prevention of cardiovascular disorder (Kinsella, 1998; Mozaffarian et al., 2005; Goodnight et al., $1982)$ chiefly presented in C. marulius $(2.08 \%)$ and $A$. anguilla (1.77\%). Conditional essential fatty acids arachidonic acid (C20:4) with its known positive effects on muscle growth, brain development and Alzheimer disease (Sanchez-Mejia and Mucke, 2010) mainly observed in $W$. atto $(0.48 \%)$ and L. Rohita $(0.4 \%)$. Well known neurological, inflammation and CVD protecting (Dyall, 2015) long chainó3 PUFAs Docosahexaenoic Acid (DHA), Eicosapentaenoic Acid (EPA) and Docosapentanoic (DPA) were identified chiefly in $L$. rohita and A. anguilla. The summation of DHA and EPA in the four species were $0.76,0.38 .1 .93$ and $1.75 \%$ in $W$. atto, C. marulius, L. rohita and A. anguilla respectively. The collective EPA+DHA role is very crucial to acquire the above remarked health welfares while DPA may act as reservoir for DHA and EPA (Kaur et al., 2013). The dietary recommendation for EPA+DHA is $500 \mathrm{mg} /$ day which can be achieved by 2 serving size (each serving size $4 \mathrm{oz}=112 \mathrm{gm}$.) of fish per week (Kris-Etherton and Innis, 2007). It was suggested that elevated level of DHA than EPA is linked with importance of cell membrane's enzymatic activity, physiological equilibrium (Watanabe, 1982) stronger immune defense system against pathogenesis, homeostatic regulation of osmotic pressure and communal conducts (Shulman and Love, 1999). The species $A$. anguilla supposed to have highest motility among the four species due to possessing highest DHA and MUFAs contents as (Bell and Sargent, 2003) deduced that breeding relocation and physical movement is allied to eminent level of DHA and MUFAs. The ratio of $\omega 6 / \omega 3$ is another way of assessing the nutrition and health benefits of a diet. Most of western countries diets are lacking in omega- 3 and have high $\omega 6 / \omega 3$ ratio. According to dietitians the recommended $\omega 6 / \omega 3$ ratio is $1-5$ and if $\omega 6 / \omega 3$ ratio of any diet lies in this range then this food might be proved as a neutraceutical and can help body against the autoimmune diseases, cardiovascular disease, cancer and inflammatory disease. The ratios of $\omega 6 / \omega 3$ detected in specimen fish species range from 1.09 to 4.71 which broaden the importance of consumption of these fish species. These findings are in accord with the findings of Yesim and Fatih (2007) according to which PUFAs are the dominating fatty acids after the saturated fatty acids and Pirini et al. (2000) according to which fresh water species is richer in the Omega- 6 fatty acids. So these fresh water fish species are rich in the $\omega 6$ fatty acids as compared to Omega-3 fatty acids. These findings are also in agreement with the findings of Rasoarahona et al. (2005) Ward and Singh (2005) who stated that among the PUFAs, in Fresh water fish species, the most abundant fatty acids are $\gamma$-Linolenic Acid (GLA) (C18:3, $\omega 6)$ and $\alpha$-linolenic acid $(\mathrm{C} 18: 3, \omega 3)$ which ranges from 1.3 to 7.70 and 0.46 to $2.37 \%$ respectively. Sargent et al. 
(1995) and Saito et al. (1999) reported that variation in the fatty acids is not only due to the cause of habitat but it also rely on the diet whether it is natural or artificial and nature of taking feed like whether the species are carnivores, herbivores or omnivores, ecological conditions like temperature and water, age, size and reproductive cycle.

In this era of curiosity, inventions and discoveries, it has, now, become very crucial to compare and characterize the fish species from different countries. Like many other developing countries Fish and other aquaculture foods are main source of superior quality protein and lipids in China, India and Turkey. A research study on fresh caught wild fish species from the Yangtz basin conducted by Zhang et al. (2014) found these low fat species deficient in short chain SFAs (C8:0, C10:0) and long chain SFAs (C22:0 and C24:0) as compared SFAs copious fresh water fish species of Pakistan. MUFAs and PUFAs are more dominant in Chinese fish species where their range is $21.83-50.53$ and 19.43$45.6 \%$ respectively but in Pakistani fish species the ranges of MUFAs and PUFAs is 25.72-31.37 and 7.4$22.76 \%$ respectively. Among the PUFAs, Pakistani fish species lacked eicosadienoic acid (C20:2n6), docosatetraenoic acid (C22:4n6) and docosapentaenoic acid (C22:5n6). The ratios of Omega3/Omega6 in Chinese species ranges from 0.25 to 1.16 and most of Chinese species have Omega3/Omega6 $>0.5$. The summation of EPA and DHA in Chinese fish species is 2.77 to $14.86 \%$ and most of them have summation of EPA and DHA $>9 \%$. So we can say that Chinese fresh water fish species are rich source of PUFAs and Pakistani Fish species are rich in SFAs. In another study carried out by Jakhar et al. (2012) on four Indian fresh water fish species found these fish species contain low to medium fat with their protein contents are also low as compared to Pakistani fish species. Among the total fatty acids, SFAs are high in Pakistani Fish species; MUFAs are high in Indian fish species whereas PUFAs are comparable. Among total FAMEs of these Indian fish species lacked (C8:0), (C10:0), (C22:0), (C23:0) and (C24:0 (C14:1), (C15:1), (C17:1), (C22:1) and $\gamma$-Linolenic Acid (C18:3 w6 GLA) (Jakhar et al., 2012). Omega3/Omega-6 ratios for Indian fish species range from 0.7 to 6.2 which indicated high quantity of Omega-3 but for Pakistani Fish species this ratio range from 0.34 to 0.94 which shows that Pakistani fish species contain more Omega- 6 fatty acids as compared to Indian fish species.

Recent study on Indian fresh water carp species conducted by (Dey et al., 2015) revealed that short and medium chain fatty acids (C8:0, C10:0 and C12:0) are absent in the Indian fish species and long chain (more than C22:0) MUFAs are not in Pakistani fish species.

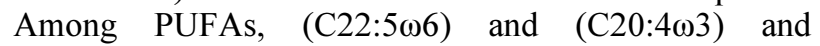
(C21:503) have not been detected in Pakistani species. But this study give us knowledge that Indian fresh water fish species are plenteous in Omega-3 PUFAs and deficient in Omega-6 PUFAs which is not the typical characteristic of fresh water fish species. Their PUFA quantity is amazingly high which ranges from 6.9 to $18.3 \%$ (Dey et al., 2015). Another study by Nath et al. (2014) has also confirmed these findings, But Cakmak et al. (2012) Identified 38 fatty acids from the wild fresh water fish species from Sugla Lake, Turkey. These Turkish fresh water fish species has less quantity of SFAs (21.43 to 21.36 to $26.33 \%$ ) as compared to Pakistan fish species 48.5-65.7\%). Among MUFAs the trend is not as flat as in SFAs. The maximum amount identified in Pakistani species is $31.3 \%$ but for Turkish fish species half of fish species have more than $31 \%$ MUFAs. Among the PUFAs, Pakistan fish species have $22.7 \%$ PUFAs maximally, however, Turkish fish species are rich in the PUFAs with maximum identified PUFAs up to $51.8 \%$ which is very enormous and amazing quantity. Pakistani Fish species contain less w3PUFAs but the quantity of $\omega 6$ PUFAs is comparable to those in Turkish fish species. While comparing outcomes of Citil at al. (2014) and Ersoy and Şereflişan (2010) on other Turkish fresh water species with our findings, we presumed the homologous results as detailed above.

\section{Conclusion}

Characterization of four selected fresh water fish was carried out with special reference to nutrition and lipid profile. In conclusion, the data from nutritional values and fatty acids profile analyses suggested us that these high fat fish species adore with bounteous sum of nutritional fractions containing substantive and functional fatty acids and amino acids and generally these species are nutritious and healthy to consume. In the FA mapping, SFAs were detected as major lipid with positive association with total lipid contents. Among SFAs, short, medium chain and odd number FAs were detected, signifying the status of under study fish species as a remedial and therapeutic diet due to their curative strikes on various ailments related to regulation of growth and digestion hormones, metabolism (glucose and cholestrol), appetite, brain seizure, scleroses and Alzheimer disease. C. marulius noticed to bear most eminent amount of SFAs among four species. Most Substantial quantity of MUFAs was detected in $W$. atto. These MUFAs are quite helpful in maintenance of "good cholesterol" level and prevention of occurrence of prostate cancer, diabetes and obesity with neutral effects on the level of bad cholesterol. Concerning PUFAs, more prevalent quantity of PUFAs was found in $L$. rohita and $A$. anguilla. The understudy fish species ascertained to be rich source of Omega-6 LC-PUFAs with low fractions of DHA and EPA. But the consumption of these species according to endorsed per serving size can meet the dietetic sanctions of EPA and DHA. $\omega 6 / \omega 3$ ratio of $L$. rohita was found to be most close to optimal $(5 / 1)$. In comparison with neighboring 
countries and Eurasian Turkeys' fresh water fish species, these understudy fish species were found to be rich in saturated lipids and short chain SFAs with low percentages of PUFAs. From this work, it is evident that all the selected fish species are the harbor of important fatty acids but the extents of their presence differ greatly from one to another. These species are the cheap source of PUFAs and other important fatty acids and by inclusion these species in food web, people can get the beneficial healthy attributes easily.

\section{Acknowledgment}

The author is pleased to state that this work is supported by Higher Education Commission of Pakistan and National Natural Science Foundation of China (Grant No. 31271812).

\section{Author's Contributions}

Ahsan Hameed: Carried out the experiment and drafted the manuscript.

Syed Ammar Hussain: Participated in FA identification and quantification.

Muhammed Asim Shabbir: Kindly guided in due analytical experimentations.

Imran Pasha and Yuanda Song: Design the experiment and critically reviewed the final manuscript.

\section{Conflict of Interest}

The authors declares that they have no conflicts of interests.

\section{Compliance with Ethics Requirement}

This article does not contain any clinical studies with human or animal subjects.

\section{References}

Ackman, R.G., 1989. Marine Biogenic Lipids, Fats and Oils. 1st Edn., CRC Press, ISBN-10: 0849348897, pp: 472 .

Ashraf, M., A. Zafar, A. Rauf, S. Meshboob and N.A. Qureshi, 2011. Nutritional values of wild and cultivated silver carp (Hypophthalmichthys molitrix) and grass carp (Ctenopharyngodon idella). Int. J. Agric. Biol., 13: 210-214.

Ayo, J., J. Carballo, J. Serrano, B. Olmedilla-Alonso and C. Ruiz-Capillas et al., 2007. Effect of total replacement of pork backfat with walnut on the nutritional profile of frankfurters. Meat Sci., 77: 173-181. PMID: 22061588

Bell, J.G. and J.R. Sargent, 2003. Arachidonic acid in aquaculture feeds: Current status and future opportunities. Aquaculture, 218: 491-499. DOI: $10.1016 / \mathrm{S} 0044-8486(02) 00370-8$
Belling, G., M. Abbey, J. Campbell and G. Campbell, 1997. Lipid content and fatty acid composition of 11 species of Queensiand (Australia) fish. Lipids, 32: 621-625. DOI: 10.1007/s11745-997-0079-z

Bernstein, A.M., M.F. Roizen and L. Martinez, 2014. Purified palmitoleic acid for the reduction of highsensitivity C-reactive protein and serum lipids: A double-blinded, randomized, placebo controlled study. J. Clin. Lipidol., 8: 612-617. DOI: $10.1016 /$ j.jacl.2014.08.001

Cakmak, Y.S., G. Zengin, G.O. Guler, A. Aktumsek and H. Ozparlak, 2012. Fatty acid composition and $\omega 3 / \omega 6$ ratios of the muscle lipids of six fish species in sugla lake, Turkey. Arch. Biol. Sci., Belgrade, 64: 471-477.

Chang, P., K. Augustin, K. Boddum, S. Williams and M. Sun et al., 2015. Seizure control by decanoic acid through direct AMPA receptor inhibition. Brain, 139: 431-443. PMID: 26608744

Chaudhry, A.S., 2008. Forage based animal production systems and sustainability, an invited keynote. Revista Brasileira de Zootecnia, 37: 78-84. DOI: $10.1590 / \mathrm{S} 1516-35982008001300010$

Citil, O.B., L. Kalyoncu and O. Kahraman, 2014. Fatty acid composition of the muscle lipids of five fish species in işikli and karacaören dam lake, Turkey. Vet. Med. Int. DOI: 10.1155/2014/936091

Cocks, L.V. and V.C. Rede, 1966. Laboratory Handbook for Oil and Fat Analysts. 1st Edn., Academic Press, London, pp: 419.

Connor, W.E., 2000. Importance of n-3 fatty acids in health and disease. Am. J. Clin. Nutr., 71: 171S-175S. PMID: 10617967

Crawford, M.A., 1993. The role of essential fatty acids in neural development: implications for perinatal nutrition. Am. J. Clin. Nutr., 57: 703S-709S. PMID: 7682751

Dayrit, F.M., 2015. The properties of lauric acid and their significance in coconut oil. J. Am. Oil Chem. Soc., 92: 1-15. DOI: 10.1007/s11746-014-2562-7

De Fabiani, E., 2011. The true story of palmitoleic acid: Between myth and reality. Eur. J. Lipid Sci. Technol., 113: 809-811. DOI: $10.1002 /$ jlt.201100187

Dey, S., K.K. Misra and S. Homechoudhuri, 2015. Lipid classes and fatty acids of a freshwater Indian minor carp, Amblypharyngodon mola. Int. J. Res. Fisher. Aquac., 5: 5-18. DOI: 10.13140/RG.2.1.3695.7520

Dyall, S.C., 2015. Long-chain omega-3 fatty acids and the brain: A review of the independent and shared effects of EPA, DPA and DHA. Front Aging Neurosci., 21: 52-52. DOI: $10.3389 /$ fnagi.2015.00052

Ersoy, B. and H. Şereflişan, 2010. The proximate composition and fatty acid profiles of edible parts of two freshwater mussels. Turkish J. Fisher. Aquatic Sci., 10: 71-74. 
Farhat, J. and C. Shakoor, 2011. Chemical compositions and fatty acid profiles of three freshwater fish species. 125: 991-996.

DOI: 10.1016/j.foodchem.2010.09.103

Fonteh, A.N., C. Ormseth, J. Chiang, M. Cipolla and X. Arakaki, 2015. Sphingolipid metabolism correlates with cerebrospinal fluid beta amyloid levels in alzheimer's disease. PLoS One, 10: e0125597e0125597. DOI: 10.1371/journal.pone.0125597

Gillingham, L.G., S. Harris-Janz and P.J.H. Jones, 2011. Dietary monounsaturated fatty acids are protective against metabolic syndrome and cardiovascular disease risk factors. Lipids, 46: 209-228.

DOI: $10.1007 / \mathrm{s} 11745-010-3524-\mathrm{y}$

Glogowski, J. and A. Ciereszko, 2001. Why we should increase food consumption, especially that of rainbow trout. Food Tech, 2: 95-102.

Goodnight, S.H.Jr, W.S. Harris, W.E. Connor and D.R. Illingworth, 1982. Polyunsaturated fatty acids, hyperlipidemia and thrombosis. Arteriosclerosis, 2: 87-113. PMID: 7039582

Guil-Guerrero, J.L., E. Venegas-Venegas, M.Á. RincónCervera and M.D. Suárez, 2011. Fatty acid profiles of livers from selected marine fish species. J. Food Compos. Analysis, 24: 217-222.

DOI: $10.1016 /$ j.jfca.2010.07.011

Holub, D.J. and B.J. Holub, 2004. Omega-3 fatty acids from fish oils and cardiovascular disease. Mol. Cell Biochem., 263: 217-225.

DOI: 10.1023/B:MCBI.0000041863.11248.8d

Horwitz, W., 2006. Official Methods of Analysis of Association of Official Analytical Chemists International. 1st Edn., The Association, Washington, DC.

Iguchi, K., N. Okumura, S. Usui, H. Sajiki and K. Hirota et al., 2001. Myristoleic acid, a cytotoxic component in the extract from Serenoa repens, induces apoptosis and necrosis in human prostatic LNCaP cells. Prostate, 47: 59-65. DOI: 10.1002/pros. 1047

Jakhar, J.K., A.K. Pal, A.D. Reddy, N.P. Sahu and G. Venkateshwarlu et al., 2012. Fatty acids composition of someselected Indian fishes. Afr. J. Basic Applied Sci., 4: 155-160.

Jayasinghe, C., N. Gotoh and S. Wada, 2003. Variation in lipid classes and fatty acid composition of salmon shark (Lamna ditropis) liver with season and gender. Comparat. Biochem. Physiol. B Biochem. Mol. Biol., 134: 287-295.

DOI: $10.1016 / \mathrm{S} 1096-4959(02) 00268-3$

Jenkins, B., J.A. West and A. Koulman, 2015. A review of odd-chain fatty acid metabolism and the role of pentadecanoic acid (C15:0) and heptadecanoic acid (C17:0) in health and disease. Molecules, 20: 2425-2444. DOI: 10.3390/molecules20022425
Kaur, G., J.C. Molero, H.S. Weisinger and A.J. Sinclair, 2013. Orally administered $\left[{ }^{14} \mathrm{C}\right] \mathrm{DPA}$ and $\left[{ }^{14} \mathrm{C}\right] \mathrm{DHA}$ are metabolised differently to $\left[{ }^{14} \mathrm{C}\right] \mathrm{EPA}$ in rats. Brit. J. Nutrit., 109: 441-448. DOI: $10.1017 / \mathrm{S} 0007114512001419$

Kinsella, J.E., 1998. Food lipids and fatty acids: Importance in food quality, nutrition and health. Food Tech., 42: 10-124.

Kolanowski, W. and G. Laufenberg, 2006. Enrichment of food products with polyunsaturated fatty acids by fish oil addition. Eur. Food Res. Technol., 222: 472-477. DOI: 10.1007/s00217-005-0089-8

Kris-Etherton, P.M. and S. Innis, 2007. Position of the American dietetic association and dietitians of Canada: Dietary fatty acids. J. Am. Diet. Assoc., 107: 1599-1611. PMID: 17936958

Kris-Etherton, P.M., W.S. Harris and L.J. Appel, 2003. Fish consumption, fish oil, omega-3 fatty acids and cardiovascular disease. Arterioscler. Thromb. Vasc. Biol., 23: 20-30.

DOI: $10.1161 / 01 . A T V .0000038493 .65177 .94$

Legrand, P., E. Beauchamp, D. Catheline, F. Pédrono and V. Rioux, 2010. Short chain saturated fatty acids decrease circulating cholesterol and increase tissue PUFA content in the rat. Lipids, 45: 975-986. DOI: $10.1007 / \mathrm{s} 11745-010-3481-5$

Lemarié, F., E. Beauchamp, S. Dayot, C. Duby and P. Legrand et al., 2015. Dietary caprylic acid (C8:0) does not increase plasma acylated ghrelin but decreases plasma unacylated ghrelin in the rat. PLoS One, 10: e0133600- e0133600.

DOI: $10.1371 /$ journal.pone. 0133600

Lovegrove, J.A., C.N. Brooks, M.C Murphy, B.J. Gould and C.M. Williams, 1997. Use of manufactured foods enriched with fish oils as a means of increasing long-chain $n-3$ polyunsaturated fatty acid intake. Brit. J. Nutr., 78: 223-236.

DOI: $10.1079 /$ BJN19970142

Luzia, L.A., G.R. Sampaio, C.M.N. Castellucci and E.A.F.S. Torres, 2003. The influence of season on the lipid profiles of five commercially important species of Brazilian fish. Food Chem., 83: 93-97. DOI: $10.1016 / \mathrm{S} 0308-8146(03) 00054-2$

Maurizio, P., T. Silvia, V. Vittoria, P. Alessandra and B. Anna, 2010. Blue-back fish: Fatty acid profile in selected seasons and retention upon baking. Food Chem., 123: 306-314. DOI: $10.1016 /$ j.foodchem.2010.04.036

Minitab Inc, 2012. Minitab Statistical Software Version 16.2.3. Minitab Inc., State College, PA. URL

Moreira, A.B., J.V. Visentainer, N.E. de Souza and M. Matsushita, 2001. Fatty acids profile and cholesterol contents of three Brazilian Brycon freshwater fishes. J. Food Composit. Analysisa, 14: 565-574. DOI: $10.1006 /$ jfca.2001.1025 
Mozaffarian, D., C.L. Bryson, R.N. Lemaitre, G.L. Burke and D.S. Siscovick, 2005. Fish intake and risk of incident heart failure. J. Am. Coll. Cardiol., 45: 2015-2021.

DOI: $10.1016 /$ j.jacc.2005.03.038

Nath, A.K. and B. Banerjee, 2012. Comparative evaluation of body composition of hilsa, Tenualosa ilisha (Hamilton, 1822) in different size groups with special reference to fatty acid, in Hooghly estuarine system, West Bengal, India. Ind. J. Fish., 59: 141-146.

Nath, A.K., A. Patra, B. Sen, D. Dey and I. Das et al., 2014. Fatty acid compositions of four edible fishes of Hooghly Estuary, West Bengal, India. Int. J. Curr. Microbiol. App. Sci., 3: 208-218.

Noto, D., F. Fayer, A.B. Cefalù, I. Altieri and O Palesano et al., 2015. Myristic acid is associated to low plasma HDL cholesterol levels in a Mediterranean population and increases HDL catabolism by enhancing HDL particles trapping to cell surface proteoglycans in a liver hepatoma cell model. Atherosclerosis, 246: 50-56.

DOI: $10.1016 /$ j.atherosclerosis.2015.12.036

O'Brien, R.D.O., 2004. Fats and Oils: Formulating and Processing for Applications. 2nd Edn., CRC Press, New York, ISBN-10: 0203483669, pp: 616.

Onyeike, E.N., E.O. Ayalogu and C.O. Ibegbulem, 2000. Evaluation of the nutritional value of some crude oil polluted freshwater fishes. Global J. Pure Applied Sci., 6: 227-233. DOI: 10.4314/gjpas.v6i2.16112

Osman, H., A.R. Suriah and E.C. Law, 2001. Fatty acid composition and cholesterol content of selected marine fish in Malaysian waters. Food Chem., 73: 55-60. DOI: 10.1016/S0308-8146(00)00277-6

Pirini, M., P.P. Gatta, S. Testi, G. Trigari and P.G. Monetti et al., 2000. Effect of refrigerated storage on muscle lipid quality of sea bass (Dicentrarchus labrax) fed on diets containing different levels of vitamin E. Food Chem., 68: 289-293. DOI: $10.1016 / \mathrm{S} 0308-8146(99) 00190-9$

Rahnan, S.A., T.S. Huah, O. Nassan and N.M. Daud, 1995. Fatty acid composition of some Malaysian freshwater fish. Food Chem., 54: 45-49. DOI: 10.1016/0308-8146(95)92660-C

Rasoarahona, J.R.E., G. Barnathan, J.P. Bianchini and E.M. Gaydou, 2005. Influence of season on the lipid content and fatty acid profiles of three tilapia species (Oreochromis niloticus, O. macrochir and Tilapia rendalli) from Madagascar. Food Chem., 91: 683-694. DOI: 10.1016/j.foodchem.2004.07.001

Regost, C., J. Arzel, J. Robin, G. Rosenlund and S.J. Kaushik, 2003. Total replacement of fish oil by soybean or linseed oil with a return to fish oil in turbot (Psetta maxima): 1. Growth performance, flesh fatty acid profile and lipid metabolism. Aquaculture, 217: 465-482.

DOI: $10.1016 / \mathrm{S} 0044-8486(02) 00259-4$
Ros, E., 2003. Dietary cis-monounsaturated fatty acids and metabolic control in type 2 diabetes. Am. J. Clin. Nutr., 78: 617S-625S. PMID: 12936956

Saify, Z.S., S. Akhtar, S. Hassan, M. Arif and F. Ahmed et al., 2000. A study on fatty acid composition of fish oil from two marine fish, Eusphyra blochii and Carcharhinus bleekeri. Pak. J. Pharm. Sci., 13: 512. PMID: 16414840

Simopoulos, A.P., 2002. The importance of the ratio of omega-6/omega-3 essential fatty acids. Biomed. Pharmacother., 56: 365-379. DOI: 10.1016/S0753-3322(02)00253-6

Saito, H., R. Yamashiro, C. Alasalvar and T. Konno, 1999. Influence of diet on fatty acids of three subtropical fish, subfamily caesioninae (Caesio diagramma and $C$. tile) and family siganidae (Siganus canaliculatus). Lipids, 34: 1073-1082. DOI: $10.1007 /$ s1 1745-999-0459-4

Sanchez-Mejia, R.O. and L. Mucke, 2010. Phospholipase $\mathrm{A}_{2}$ and arachidonic acid in Alzheimer's disease. Biochim. Biophys. Acta, 1801: 784-790.

DOI: $10.1016 /$ j.bbalip.2010.05.013

Sargent, J.R., J.G. Bell, M.V. Bell, R.J. Henderson and D.R. Tocher, 1995. Requirement criteria for essential fatty acids. J. Applied Ichthyol., 11: 183-198. DOI: $10.1111 / \mathrm{j} .1439-0426.1995 . t b 00018 . x$

Shulman, G.E. and R.M. Love, 1999. The Biochemical Ecology of Marine Fishes. In: Advances in Marine Biology, Southward, A.J., P.A. Tyler and C.M. Young (Eds.), Elsevier, London, ISBN-10: 012026143X, pp: 351-351.

Steel, R.G.D., J.H. Torrie and D. Dickey, 1997. Principles and Procedures of Statistics: A Biometrical Approach. 3rd Edn., McGraw-Hill, New York, ISBN-10: 0070610282, pp: 336-352.

Uauy, R. and A. Valenzuela, 2000. Marine oils: The health benefits of $n-3$ fatty acids. Nutrition, 16: 680684. DOI: $10.1016 / \mathrm{S} 0899-9007(00) 00326-9$

Ward, O.P. and A. Singh, 2005. Omega-3/6 fatty acids: Alternative sources of production. Process Biochem., 40: 3627-3652. DOI: 10.1016/j.procbio.2005.02.020

Waseem, M.P., 2007. Issues, growth and instability of inland fish production in Sindh (Pakistan) spatialtemporal analysis. Pak. Econom. Social Rev., 45: 203-230.

Watanabe, T., 1982. Lipid nutrition in fish. Comparat. Biochem. Physiol. Part B: Comparat. Biochem., 73: 3-15. DOI: 10.1016/0305-0491(82)90196-1

Wedoud, O.L., M.G. Emile and V.O.K. Mohamed, 2011. Muscle lipids and fatty acid profiles of three edible fish from the Mauritanian coast: Epinephelus aeneus, Cephalopholis taeniops and Serranus scriba. Food Chem., 124: 24-28. DOI: 10.1016/j.foodchem.2010.05.097 
$\mathrm{Wu}$, G., 2010. Functional amino acids in growth, reproduction and health. Adv. Nutrit., 1: 31-37. DOI: $10.3945 /$ an. 110.1008

$\mathrm{Wu}$, G., 2013. Functional amino acids in nutrition and health. Amino Acids, 45: 407-411. DOI: $10.1007 / \mathrm{s} 00726-013-1500-6$

Yesim, Z. and Z. Fatih. 2007. Fatty acid profiles of commercially important fish species from the Mediterranean, Aegean and Black Seas. Food Chem., 100: 1634-1638.
Zhang, Z., L. Liu, C. Xie, D. Li and J. Xu et al., 2014. Lipid contents, fatty acid profiles and nutritional quality of nine wild caught freshwater fish species of the Yangtze Basin, China. J. Food Nutrit. Res., 2: 388-394. DOI: $10.12691 / j$ fnr-2-7-10

Zygmunt, U., S.R. Joanna and A. Maria, 2012. Variations in proximate composition and fatty acid profiles of Baltic sprat (Sprattus sprattus balticus). Food Chem., 130: 97-103.

DOI: 10.1016/j.foodchem.2011.07.003 